\title{
An Alternative Technique for Treating Complex Ureteral Strictures and Defects using A Peritoneal Graft
}

\author{
Trenti Emanuela ${ }^{1 *}$, Palermo Salvatore M, D Elia Carolina, Comploj Evi, Ladurner Christian, Huqi Dorian, \\ Tischler Tamara, Mian Christine and Armin Pycha ${ }^{2}$
}

${ }^{1}$ General Hospital of Bolzano, Department of Urology, Italy

${ }^{2}$ Sigmund Freud Private University, Medical School, Vienna, Austria

Received: October 27, 2017; Published: October 31, 2017

*Corresponding author: Emanuela Trenti, Department of Urology, Hospital of Bolzano, Bolzano, Italy, Tel: +390471 908686;

Email: trentiemanuela@yahoo.it

\begin{abstract}
Purpose: To describe a new technique of ureteral reconstruction using a free peritoneal graft.

Methods: Between 2006 and 2015 we identified 8 patients with complex ureteral strictures involving in 7 cases the middle ureter. Stricture length ranged from 4 to $12 \mathrm{~cm}$. Two cases were secondary to long strictures from retroperitoneal fibrosis after vascular surgical, 3 cases followed an extensive resection, required for large intraureteral masses, 2 cases were secondary to repeated endoscopic procedures for urinary stones and 1 case followed repeated pyeloplastics. After ureteral incision a free peritoneal graft was harvested from nearby healthy peritoneum. An onlay patch was fixed with running suture to the remaining ureteral plate after placement of an ureteral catheter. The ureter was wrapped with omentum.
\end{abstract}

Results: Follow-up has ranged from 14 to 76 months. Five patients were free from recurrence after 6, 30, 36, 54 and 60 months, showing good passage of the contrast without dilatation of the upper urinary tract on the uro-CT/urography. In 2 patients occurred a recurrence below the reconstructed ureter after 6 and 60 months without symptoms and with mild hydronephrosis. The last patient showed asymptomatic obstruction of the reconstructed segment with hydronephrosis of the upper pole system 6 months after the procedure. The limitation of this study is the small sample series, due to the selective indications.

Conclusion: This technique allows for preservation of any remaining vascular supply of the ureter and can be a feasible and use full alternative to nephrectomy, ileal ureter and autotransplantation in highly selected cases.

Keywords: Peritoneal Graft; Complex Ureteral Stricture; Middle Ureter; Ureter Reconstruction

\section{Introduction}

Mid-ureteral strictures and defects with or without involvement of the upper urinary tract represent one of the most serious reconstructive challenges for urologists and might require more complex treatment like bowel replacement or auto transplantation. These procedures are of considerable magnitude and associated with high rates of complications and long term morbidity [1-3]. Based on the evidence that atonic ureters affected by schistosomiasis can drain well by gravity [4-6] and on the success of buccal mucosal graft in the repair of complicated hypospadias [7,8] in 1999 Naude described a new technique using buccal mucosal graft for treating complicated ureteral strictures with good results [9]. Starting from our experience in urethral reconstruction with buccal mucosal graft, we describe a new alternative technique of ureteral reconstruction using a free peritoneal graft in 8 highly selected cases. Written informed consent was collected from all patients before intervention.

\section{Materials and Methods}

Between January 2006 and December 2015, 8 patients with mid-ureteral narrowing and obstruction and/or with complex ureteral stricture were treated using a peritoneal graft. Stricture/ defect length ranged from 4 to $12 \mathrm{~cm}$. Due to their length, all cases would have otherwise required an ileal ureter, nephrectomy or auto transplantation. Two cases were secondary to long strictures from retroperitoneal fibrosis after vascular surgical procedures, three cases followed an extensive resection, required for large intraureteral masses ( 2 papillomas and 1 pTaG1) resulting in insufficient ureteral width for closure, 2 cases was secondary to repeated endoscopic procedures for urinary stones and 1 case followed repeated open pyeloplastics (with involvement of a long part of proximal ureter). The surgical procedure was performed with extraperitoneal exposure of strictured ureter in 7 patients while in 1 was performed transperitoneally. 
Table 1: Characteristics of the operated ureteral strictures.

\begin{tabular}{|c|c|c|c|c|c|}
\hline Pts & Cause of Stricture & Stricture Length & Stricture Number & Stricture Localization & Follow up Months \\
\hline 1 & Previous vascular procedure & 12 & 1 & prox/mid ureter & 60 \\
\hline 2 & Papilloma G0 & 5 & 1 & mid ureter & 76 \\
\hline 3 & Papilloma G0 & 7 & 1 & mid ureter & 56 \\
\hline 4 & Previous vascular procedure & 12 & 1 & mid ureter & 54 \\
\hline 5 & pTaG1 & 4 & 1 & mid ureter & 36 \\
\hline 6 & $\begin{array}{l}\text { Previous endoscopic surgery in one of the } 2 \\
\text { ureters on the left side }\end{array}$ & 6 & 1 & prox/mid ureter & 26 \\
\hline 7 & Previous endoscopic surgery & 12 & 2 & prox/mid ureter & 15 \\
\hline 8 & Previous open pyeloplasty (x 4) & 5 & 1 & proximal ureter & 14 \\
\hline
\end{tabular}

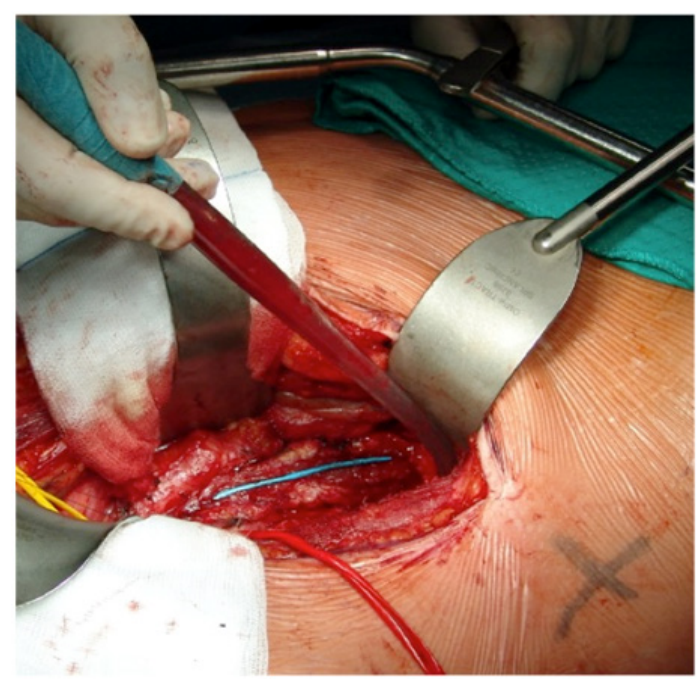

Figure 1: The ureter with an indwelling ureteral stent before the beginning of the Reconstruction.

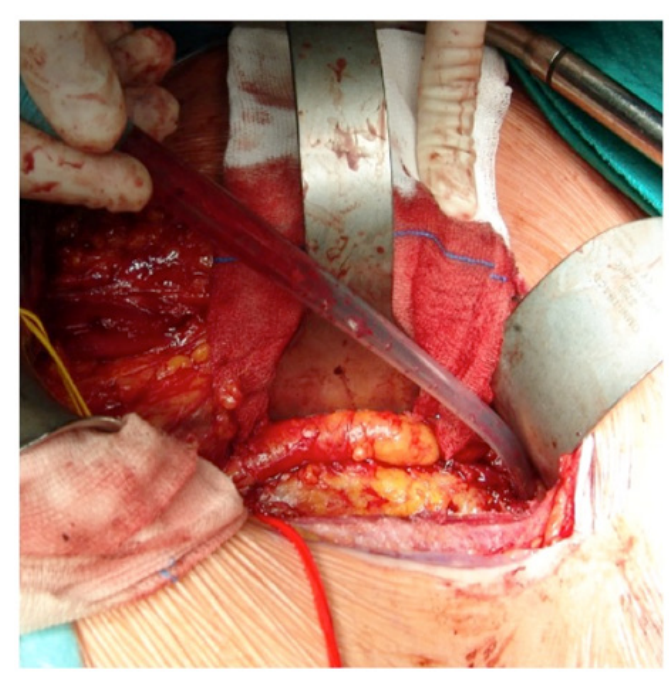

Figure 2: Final result of the ureteral reconstruction with peritoneal patch.

After identification of the strictured ureteric segment, the narrow segment was opened longitudinally and the incision was extended for $1 \mathrm{~cm}$ in both directions into healthy ureter, preserving the longitudinal ureteral adventizial vessels to support the vascularization of the graft; a free peritoneal graft of appropriate dimension was harvested from nearby healthy peritoneum, shaped to appropriate size and fixed with running 5/0 Monocryl suture to the remaining ureteral plate after placement of an indwelling ureteral catheter (Figures 1 \& 2). Finally, the greater omentum was mobilized to cover completely the reconstructed area and secured with absorbable interrupted suture (Table 1). The wound was drained with a 24 Chavier drain and a transurethral catheter was inserted into the urinary bladder for 10 days to ensure a zero degree pressure system. A cystography was performed after 10 days to show the patency of the ureter and the absence of extravasation: if the suture line was watertight, the transurethral catheter was removed; otherwise it remained in place for an additional week or more. The ureteral catheter was removed after 6 weeks or 3 months, depending on the length of the stricture and on the presence of extravasation, and an intravenous pyelography was done after removal to show the patency of the reconstructed ureter.

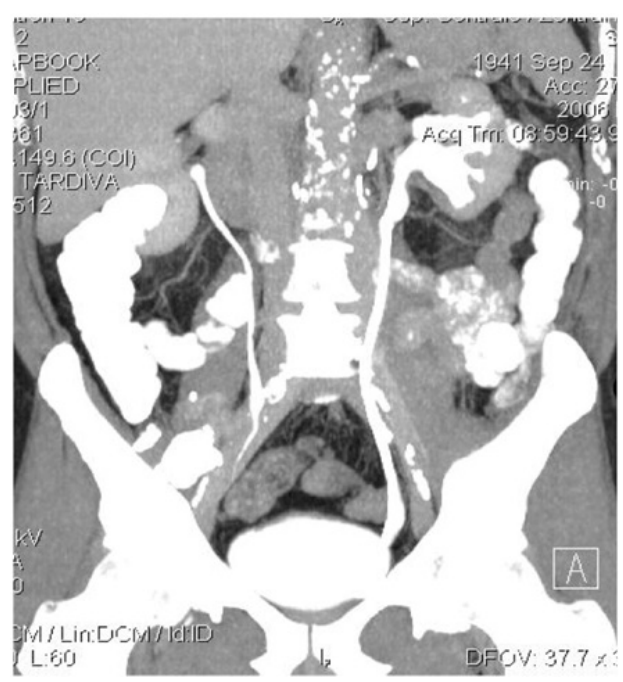

Figure 3: Free passage of the contrast through the operated ureter without dilatation of the upper urinary tract on the uro-CT one year after the reconstruction.

\section{Results}

A total of 8 ureteral reconstructions with peritoneal graft were successfully performed in 8 patients. All postoperative courses were uneventful without any major complications. The urethral catheter was removed after cystography on the 10th postoperative day in 3 patients, after 3 weeks in 4 patients and after 6 weeks in the other one. The ureteral stent was removed six weeks postoperatively in 3 patients and after 3 months in the other 5 patients. 
After removal of the ureteral catheter all patients became an intravenous pyelography, which showed the patency of all ureteral reconstructions except in one patient, who became symptomatic and required the insertion of another stent. Patient follow-up has ranged from 14 to 76 months (average 42.1 months). Five patients $(62.5 \%)$ were free from stricture recurrence after 14, 36, 54, 56 and 60 months, showing free passage of the contrast through the operated ureter without dilatation of the upper urinary tract on the uro-CT or urography and normal renal function (Figures $3 \& 4$ ). A stricture recurrence below the reconstructed ureter occurred 60 and 6 months after the procedure in 2 patients (25\%). The first of these was operated for a large intraureteral mass and the length of patch was $5 \mathrm{~cm}$.

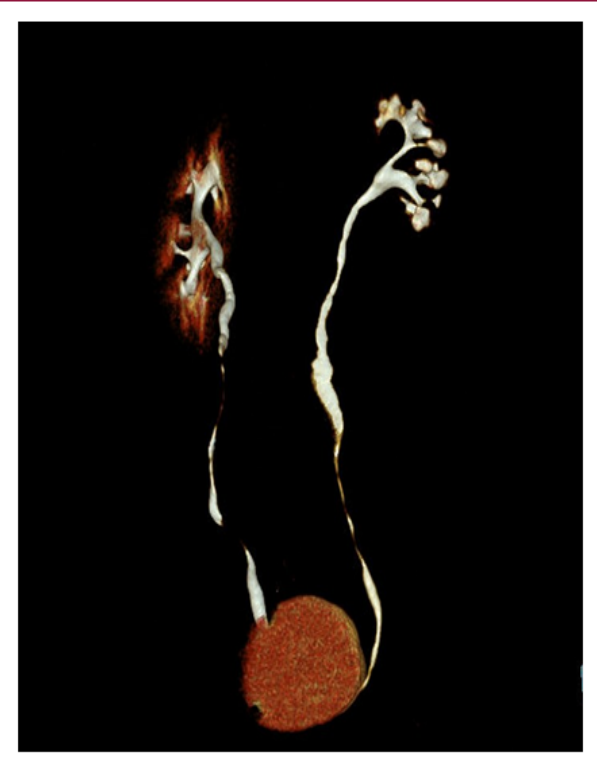

Figure 4: Another example of free passage of the contrast through the operated left ureter on the uro-CT five years after the reconstruction.

After 60 months the patient developed a recurrence below the reconstructed ureter without symptoms, with mild hydronephrosis at the urography and with minimal worsening of the renal function: he didn't required surgery and died 16 months later with stable disease at 92 years. The second patient was operated for a long double stricture of a length of $12 \mathrm{~cm}$ after repeated endoscopic operations for urinary stones and after radiotherapy and robotic radical prostatectomy for a prostate tumor. For the persistence of extravasation he needed the urethral catheter for 6 weeks; after the removal of the stent, 3 months after the operation, he became symptomatic and after temporary stenting, also this patient became asymptomatic with narrowing of the ureter below the reconstructed patent ureteric segment and hydronephrosis at the urography. A reoperation was not an option for this patient, who refused other attempts to save the kidney. In the last patient (12.5\%), who had a partial duplicated ureter, the intravenous urography showed obstruction of the reconstructed segment of the upper pol ureter with hydronephrosis of the upper pole system 3 months after removal of the ureteral catheter ( 6 months after the surgical procedure); the patient was completely asymptomatic and the obstruction was occasionally found during the control examination; the lower pol system showed a good drainage and the patient didn't required surgery.

\section{Discussion}

The ureteric strictures can be caused by several factors like stones, infections, fibrosis, malignancy, radiotherapy or in most cases by iatrogenic surgical trauma occurred during gynecological, colorectal and vascular surgery or after endourological surgery [1012]. The strictures, that are too long or not suitable for treatment with end to end anastomosis, Boari flap or Psoas hitch technique, may require an ileal ureter, autotransplantation or nephrectomy. These procedures are complex and associated with high risk of complications specially in unprepared patients in emergency situations. Further more, if the stricture involves the middle ureter, the risk of ischemic necrosis, due to the reduced vascular supply of this segment, can be high even for shorter lesions and an end to end anastomosis is not recommended even if feasible, As alternative to these complex procedures, based on the evidence that atonic ureters affected by schistosomiasis can drain well by gravity and on the success of buccal mucosal graft in the repair of complicated hypospadias, Naude and other Authors [13-15] have reported the successfull use of buccal mucosal patch graft for the reconstruction of a variety of ureteric lesions without major complications. [1618] Animal experiments have showed, that a free peritoneal graft, used as bladder substitute, works like a multipotent matrix for urethelialization of the reconstructed area, supporting the migration of the smooth muscle cells from the edges of the defects in a centripetal direction [19-21].

A free peritoneal graft was already successfully used in cardiovascular surgery and in gastrointestinal surgery [22-23]. In urology a pediculated peritoneal graft was initially used for cistoplasty and closure of vesicovaginal fistulae [24] but a free peritoneal graft was used for the first time in animal experiments for bladder repair with good results from Hutschenreiter [25]. Thueroff [26] used a free peritoneal graft to cover defects of the renal pelvis not suitable for primary closure or to envelope renal pelvis and/or ureter to reduce the risk of extrinsec obstruction, due to scarring in 31 patients, with good results in 25. Stadie et al. had good results in 29 out of 30 patients in a similar study. Encouraged from these studies, we have treated these 8 selected patients with long mid-ureteral strictures and with complex ureteral strictures, using a free peritoneal patch graft, wrapped with greater omentum. In five patients we achieved good urographic results and actually they are still free from recurrence. One patient developed a stricture recurrence after 5 years but during all this period he maintained normal renal function without complications related to the procedure.

In the other patient with recurrence, the multiple operations for urinary stones and especially the preceding radiotherapy have probably caused the persistence of extravasat and favoured the stricture below the reconstructed ureter. The last patient with partial double district, who developed the obstruction of the reconstructed segment of the upper pol ureter, was admitted to the hospital some months before with hydronephrosis of the upper pol and reduction of parenchima, due to a $2,5 \mathrm{~cm}$ stone in the 
proximal duplicated ureter: He underwent to repeated endoscopic procedures without success and with persistence of the stone. We attempted to remove the stone with open surgery and the ureter was closed with a peritoneal graft. The poor urinary drainage of the upper pol has failed to maintain the patency of the reconstructed ureter and so, probably, in this case no type of reconstruction was indicated. The advantage of this technique is the unlimited availability of the material, which can be simply harvested from nearby healthy peritoneum without related complications.

Furthermore this technique of reconstruction is simple and associated with a lower rates of complications and long term morbidity; it allows a good drainage of the upper tract and patency of the ureter, preserving as much as possible the vascular supply and reducing the risk of ischemic necrosis. In addition it can be used in unprepared patients in emergency situation to avoid more complex procedure. The limitations of this study are the small sample series and its retrospective nature. Our results are however encouraging and to our knowledge, this is the first paper which describes the use of a free peritoneal patch graft for the treatment of strictures of the middle segment of the ureter.We think, that this approach should be considered in all patients, who would need ureteric replacement for long mid-ureteral strictures, and specially in those with renal impairment, to avoid metabolic problems or increasing morbidity.

\section{Conclusion}

Mid-ureteral strictures and defects represent one of the most serious reconstructive challenges for urologists. We describe a novel technique for treating long mid-ureteral strictures or defects using a peritoneal graft with Omental wrapping. This technique allows for preservation of any remaining vascular supply of the ureter and can be a feasible and useful alternative to nephrectomy, ileal ureter and auto transplantation in highly selected cases.

\section{References}

1. Bazeed MA, El-Rakhawy M, Ashamallah A (1983) Ileal replacement of the bilharzial ureter: Is worthwhile? J Urol 130(2): 245-248.

2. Benson MC, Ring KS, Olsson CA (1990) Ureteral reconstruction and by pass: experience with ileal interposition, the Boari flap-psoas hitch and renal autotransplantation. J Urol 143: 20-23.

3. Bonfig R, Gerharz EW, Riedmiller H (2004) Ileal ureteric replacement in complex reconstruction of the urinary tract. BJU Int 93: 575-580.

4. Powell SJ, Engelbrecht HE, Welchmann NM (1968) Hydronephrosis and urinary tract bilharzias: a radiological and necropsy survey. Trans Roy Soc Tropical Med Hygiene 62(2): 231-237.

5. Sommerville JJF, Naude JH (1984) Segmental ureteric replacement: an animal study using a free non-pedicled graft. Urol Res 12: 115-119.

6. Naude JH (1984) The natural history of ureteric bilharzia. BJU 56: 599601.

7. Duckett JW, Coplen D, Baskin LS (1995) Buccal mucosal urethral replacement. J Urol 153(5):1660-1663.
8. Naude JH (1999) Buccal mucosal grafts in the treatment of ureteric lesions. BJU International 83(7):751-754.

9. Chow GK, Patterson DE, Blute ML (2003) Ureteroscopy: effect of technology and technique on clinical practice. J Urol 170(1): 99-102.

10. Georgescu D, Multescu R, Geavlete B (2014) Intraoperative complications after 8150 semirigid Ureteroscopies for ureteral lithiasis: risk analysis and management. Chirurgia 109: 369-374.

11. Burks FN, Santucci RA (2014) Management of iatrogenic ureteral injury. Ther Adv Urol 6 (3): 115-124.

12. Kroepfl D, Loewen H, Klevecka V (2009) Treatment of long ureteric strictures with buccal mucosal grafts. BJU Int 105(10): 1452-1455.

13. Agrawal V, Dassi V, Andankar MG (2010) Buccal mucosal graft onlay repair for a ureteric injury following a pyeloplasty. Indian J Urol 26(1): 120-122.

14. Sadhu S, Pandit K, Roy MK (2011) Buccal mucosa Ureteroplasty for the treatment of complex ureteric injury. Indian J Surg 73(1): 71-72.

15. Shah SA, Ranka P, Visnagara M, Sharad Dodia, Rajesh Jain (2003) Use of buccal mucosa as onlay graft technique for benign ureteric strictures. Indian J Urol 20(1): 28-32.

16. Trapeznikova MF, Bazaev VV, Shibaev AN, Luk'ianchikov AG, Vinogradov AV (2014) Replacement plastic reconstruction of extended ureteral stricture using buccal mucosa autograft. Urologija 2: 16-19.

17. Badawy AA, Abolyosr A, Saleem (2010) Buccal mucosa graft for ureteral stricture substitution: initial experience. Urology 76(4): 971-976.

18. Tsaturyan A, Akopyan K, Levonyan A (2016) Long ureteric stricture replacement by buccal mucosa graft: an Armenian experience case series report. Cent Eur J Urol 69(2): 217-220.

19. Hohenfellner R (1965) Experimentelle und klinische Untersuchungen über die Peritoneallappenplastik der Harnblase. Ann Univ Sarav (Med) 12: 108.

20. Fadali AM, Ramos MD, Topaz SR (1970) The use of autogenous peritoneum for heart valve replacement. J Thorac Cardiovasc Surg 60(2): 188-195.

21. Gyurko G, Czehelmik R (1971) Closure of wounds of the stomach and pancreas with tissue adhesive and autoplastic peritoneum patch. An experimental study. Am Surg 37: 761.

22. Hohenfellner R, Janisch H, May P (1966) Zur Therapie gynäkologischer Harnleiter-und Blasenverletzungen. Urol Int 21: 452-464.

23. Tsuji I, Kuroda K, Fujieda J, Yuzou Shiraishi, Tsuyoshi Kassai et al. (1963) A clinical and experimental study on cistoplasty not using the intestine. J Urol 89(2): 214-225.

24. Hutschenreiter G, Rumpelt HJ, Klippel KF (1978) The free peritoneal transplant as a substitute for the urinary bladder wall. Invest Urol 15(5): 375-379.

25. Thüroff G, Hutschenreiter G, Frohneberg D (1981) Transplantation of a free peritoneal patch in surgery of the renal pelvis and ureter. Eur Urol 7 1981; 7(5): 304-311.

26. Stadie G, Schneider HJ, Brundig P (1981) Die Anwendung freier Peritoneallappen bei Operationen am Nierenbecken und Harnleiter. Urologe A 20: 246-249. 


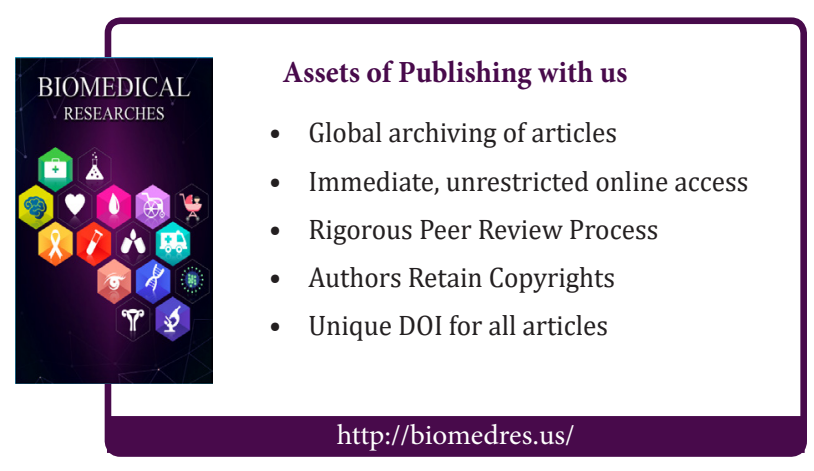

